\title{
The pharmacokinetic (PK) interaction between omeprazole and TMC278, an investigational non-nucleoside reverse transcriptase inhibitor (NNRTI)
}

\author{
HM Crauwels*1, RPG van Heeswijk ${ }^{1}$, D Kestens ${ }^{1}$, M Stevens ${ }^{1}$, A Buelens ${ }^{1}$, \\ $\mathrm{K}_{\text {Boven }}{ }^{2}$ and RMW Hoetelmans ${ }^{1}$
}

Address: ${ }^{1}$ Tibotec BVBA, Mechelen, Belgium and ${ }^{2}$ Tibotec Inc, Yardley, USA

* Corresponding author

from Ninth International Congress on Drug Therapy in HIV Infection

Glasgow, UK. 9-13 November 2008

Published: 10 November 2008

Journal of the International AIDS Society 2008, I I (SuppI I):P239 doi:I0.I I86/I758-2652-II-SI-P239

This abstract is available from: http://www.jiasociety.org/content/I I/SI/P239

(c) 2008 Crauwels et al; licensee BioMed Central Ltd.

\section{Purpose of the study}

TMC278 is a next-generation investigational NNRTI with potent and sustained efficacy through 96 weeks in ARVnaïve patients [1]. The current trial evaluated the PK interaction between omeprazole and TMC278. Omeprazole increases gastric $\mathrm{pH}$, which can affect the solubility and gastro-intestinal absorption of TMC278. Furthermore, TMC278 has been shown to induce CYP2C19 in vitro, which may influence the omeprazole PK.

\section{Methods}

This was an open-label, randomized, 2-way crossover trial in 16 HIV-negative volunteers. In two sessions, separated by a 14-day washout, participants received TMC278 150 mg QD alone (11 days), and omeprazole $20 \mathrm{mg}$ QD (22 days) with co-administration of TMC278 $150 \mathrm{mg}$ QD (day 12-22). All treatments were taken following breakfast. Steady-state 24-hr PK profiles of TMC278 were assessed on the last day of each session and steady-state 24-hr PK profiles of omeprazole and its metabolite 5hydroxy $(\mathrm{OH})$-omeprazole (formed via CYP2C19) were assessed without (day 11) and with (day 22) co-administration of TMC278. PK parameters were calculated using non-compartmental analysis. The $\mathrm{AUC}_{24} \mathrm{~h}$ ratio of 5-OHomeprazole to omeprazole was used as a surrogate marker of CYP2C19 activity. Least square (LS) means and associated $90 \%$ CI of treatment ratios (test/reference) were calculated based on log-transformed PK parameters.
When combined with omeprazole, the TMC278 steadystate $\mathrm{AUC}_{24 \mathrm{~h}}$ decreased by $40 \%$ (LS mean ratio $0.60,90 \%$ CI 0.51-0.71) compared to administration of TMC278 alone, and the steady-state $\mathrm{C}_{\max }$ and $\mathrm{C}_{\min }$ decreased by $40 \%(0.60,90 \%$ CI $0.48-0.73)$ and $33 \%(0.67,90 \%$ CI $0.58-0.78)$, respectively. TMC278 at steady state decreased the omeprazole $\mathrm{AUC}_{24 \mathrm{~h}}$ by $14 \%(0.86,90 \% \mathrm{CI}$ $0.76-0.97)$. Repeated doses of TMC278 resulted in a $27 \%$ increase of the $\mathrm{AUC}_{24 \mathrm{~h}}$ ratio of 5-OH-omeprazole to omeprazole $(1.27,90 \% \mathrm{CI} 1.18-1.36)$. The latter suggests weak induction of CYP2C19 by TMC278 $150 \mathrm{mg}$ QD, an effect which will likely be less at lower doses, and is unlikely to result in clinically relevant interactions. TMC278 alone or in combination with omeprazole was generally well tolerated. No grade 3 or 4 adverse events (AEs) and no serious AEs were reported. There were no discontinuations due to AEs.

\section{Conclusion}

These results confirm the $\mathrm{pH}$-dependent bioavailability of TMC278 and indicate that proton pump inhibitors and TMC278 25 mg QD (selected dose for Phase III) should not be co-administered. As an alternative, $\mathrm{H}_{2}$-antagonists can be used, if taken 12 hours before or 4 hours after TMC278 [2].

\section{References}

I. Santoscoy M, et al.: TMC278, an investigational next-generation NNRTI, demonstrates long-term efficacy and tolerabil- 
ity in ARV-naïve patients: 96-week results of study C204. XVIlth WAC, Mexico City, Mexico, 3-8 August 2008 . Abstract TUABOI03.

2. van heeswijk $R$, et al:: The pharmacokinetic interaction between famotidine and TMC278, a next-generation NNRTI, in HIV-negative volunteers. 4th IAS Conference on HIV Pathogenesis, Treatment and Prevention, Sydney, Australia, 22-25 July 2007. Abstract TUPDBOI

Publish with Bio Med Central and every scientist can read your work free of charge

"BioMed Central will be the most significant development for disseminating the results of biomedical research in our lifetime." Sir Paul Nurse, Cancer Research UK

Your research papers will be:

- available free of charge to the entire biomedical community

- peer reviewed and published immediately upon acceptance

- cited in PubMed and archived on PubMed Central

- yours - you keep the copyright

Submit your manuscript here:

http://www.biomedcentral.com/info/publishing_adv.asp 